\title{
Investigation of Performance of Solar Flat and Curved Plate Collectors through Numerical Simulations
}

\author{
Luqman Ahmed Pirzada ${ }^{1 a}$, Xiaoli Wu ${ }^{1 b}$, Qaiser Ali ${ }^{2}$, Asif Khateeb ${ }^{3}$, \\ AlaEldin Mohamed Tairab ${ }^{1 c}$
}

RECEIVED ON 29.01.2020, ACCEPTED ON 19.05.2020

\begin{abstract}
Solar energy is radiant light as a form of thermal heat energy which can be obtained and used by means of a variety of solar apparatus. As apparatus the flat and curved plate solar collector is specifically designed for assembling solar energy as a solar water heater system. The designing potency of this collector lone can generate medium level hot water from radiant sunlight source via absorbed plates. Standard type flat and curved plates solar collector plates are mostly used in remote coldest regions of the world where hot water is consumed for commercial and domestic purposes. These types of solar collector Plates can cheaply be manufactured compared to other solar panels like solar Shingles, Polycrystalline Solar Panels, Monocrystalline Solar Panels, and Thin Film Solar Panels. For future work, this proposed pre-design is recommended for fabrication. A numerical study was carried-out on eight city locations in China by tracing their horizontal and vertical longitudinal, latitudinal lines noting the date, time and sunlight feeding of temperatures in the Celsius scale with the help of simulation and modeling tools like CFD, ANSYS FLUENT software, mesh geometry tools, and by using the Navier-Stokes and Continuity equations by fluid flow discharge rate, mass flow, water temperature and dropping of temperature, radiation working mechanisms, dimensions of water flowing tubes and absorber plates, density, the velocity of water as the working fluid, the viscosity of water in a cold and hot state as a process of Pre-design. Work also focuses on the comparison between flat plate collector and curved plate collector radiant sunlight absorption, As end result it is found the Curved plate collector produces $22 \%$ more elevated heat of outgoing water than flat plate collector.
\end{abstract}

Keywords: Flat and Curved Plate Solar Collectors, CFD, ANSY FLUENT, Mesh Software, Navier-Stokes and Continuity equation.

\section{INTRODUCTION}

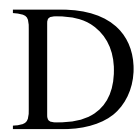
ue to increased worldwide demand for energy, there is a need to go for emission lessening type of renewable energy for power generations and other purposes. Out of the number of renewable energies the solar energy is comparatively cheaper and naturally available in abundance in many areas around the World. Solar power generation demand has increased worldwide during these days [1]. About $76 \%$ of different types of solar energy collectors are installed in China compared to rest of the world which is a thoughtful visionary trend of consumption of thermal-based solar power systems [2]. China policymakers are emphasizing on the implementation of renewable energy policies and laws to lessen environmentally-oriented pollution and promotion of social and economical sustainable development [3,4] worldwide. Renewable energies are about $20 \%$ replenished from natural sources of

${ }^{1}$ College of Mechanical and Electrical Engineering, Hohai University, Changzhou, China.

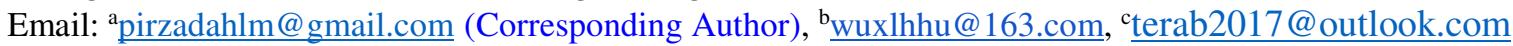

${ }^{2}$ College of Mechanical and Electrical Engineering, Nanjing University of Aeronautics and Astronautics, Nanjing,

China. Email: qaiser.ali@nuaa.edu.cn

${ }^{3}$ College of Internet of Things, Changzhou, Hohai University, China. Email: asifkhateeb097@ gmail.com

This is an open access article published by Mehran University of Engineering and Technology, Jamshoro under CC BY 4.0 International License. 
power such as biomass, wind, sunlight, geothermal, rain and tidal waves of water bodies. But still inappropriately about $80 \%$ of conventional fossil fuels are used for acquiring needs of energy for generation of electricity for industrial, commercial and domestic units, and as a fuel for transportation and a number of other commercial uses. In order to stop environment impairment there is a need to reduce the use of fossil fuels [5]. Worldwide research in this area reveals that the high percentage of fossil fuels combustion disbalances clean eco-system by receiving contaminated emissions like carbon dioxide and number of other contaminated air pollutants. These pollutants contaminant the clean environment and cause depletion of clean air quality of our planet. They also cause rise in global temperature (approximately $1.5^{\circ} \mathrm{C}$ ) [6-7]. Utilization of solar energy as a source of energy gives many important compensations regarding lessening of pollution especially $\mathrm{CO}_{2}$ emissions and in addition, induce environmental friendly energy which may fulfill the national level needs of energy crises and overall $\mathrm{CO}_{2}$ emissions mitigation and energy protection by making renewable energy [8]. To improve the scarcity of assets, less use of fossil energy consumption, and development of the competence of resources of green energy, Chinese Government is doing commendable work. The best example is the Wuhan, the capital city of the province Hubei. The population of this city is about 11 Million people. On the rooftops of urban areas of this city, photovoltaic units have been installed on large scale [9-10]. The performance of water flow in solar plate collector systems is found workable with the help of the Computational Fluid Dynamics (CFD) simulations with greater efficiency, high density and required thermal conductivity. The computation based on numerical data collected reveal that the temperature of the water and the air was upraised up to $79^{\circ} \mathrm{C}$ and 73 ${ }^{\circ} \mathrm{C}$ respectively [11]. In China, from the year 1995 onwards the solar thermal industry started to establish and with passing time it increased promptly up to 10 million $\mathrm{m}^{2}$. Its typical yearly increase rate in the year 2002 reached around thirty-one percent and in the year 2013, it reached up to seventy percent of the whole world's capacity and now counted as the capacity of the second largest country [12]. Compared to other renewable energies, solar energy is viable and easily available in abundance quantity. It is low in cost and environment friendly [13]. Among the number of Solar energy panels, Solar Flat Plate Collector (SFPC) and Solar Curved Plate Collector (SCPC) have always remained an economical and easy choice for harnessing solar energy. Studies have been conducted in different directions on SFPC and SCPC regarding the understanding of their working mechanism Satisfactory [14]. Pre-fabrication of solar plates designing is successfully done by applying CFD and other software tools for fabrication of the mild Steel considered for the absorber Plate [15].

\section{DEVELOPMENT OF CFD MODEL}

The CFD application is mostly based on fluid movement on both compressible as well as incompressible liquids plus heat transfer with help of the mathematical computational models. The CFD techniques are functional on flow phenomena of laminar and turbulent mostly mechanical and also unlike chemical reactions employ computer based simulation. CFD models are used in a variety of areas of research for industrial purposes as well for designing number of objectives before the stage of fabrication or manufacturing. CFD techniques support ANSYS FLUENT and meshing Software, which is capable and efficient to solve simulation oriented modeling and ultimately achieves accurate and viable results.

In a typical CFD simulation, a mathematical model of the physical system under consideration is used. An appropriate numerical method is used to obtain the desired results. For instance, the Navier-Stokes (N-S) equations may be specified as the mathematical model of the physical system. This describes changes in all the physical properties of both fluid flow and heat transfer.

The CFD analysis in this research work on the solar radiation heat transfer from solar rays to hot water generating is especially beneficial in cold temperature areas of China. There are some steps in the development of the CFD model known as preprocessing and post-processing. In pre-processing, a meshed geometry of the selected system is developed using some advanced software. The meshed geometry 
is technically called "computational domain". This geometry further describes the domain and divides further into sectors of mesh making for determining quandary boundary situations. The post-processing yields the outcome of the model. One can obtain desired results accurately and efficiently as a result of post-processing phase. The outputs can be examined by virtue of color plots by suitable graphical reports. This study on three dimensional geometries of SFPC and SCPC was developed in ANSYS DesignModeler® and meshed in ANSYS-Meshing ${ }^{\circledR}$. The ANSYS Design Modeler is used to make and amend the geometry and it is applied to discover the mode of generating two-dimensional drawings and change them into three-dimensional geometry. It produces line stiff plus relevant cross-sections for making Finite Element (FE) beam examination and appropriately handles its constraints. Meshing is an integral part of the engineering simulations. In Meshing, complex geometries are converted into simple elements. These elements are basically local approximations of the larger domain. The mess helps to produce accurate results with reasonably faster speed.

In Fig.1, two different types of computational domains of solar collectors are shown. Fig.1 (a) and (b) illustrate curved and flat plate dimensions and mesh in sequence in computational based design as Solar Collectors for the proposed design. The overall dimensions and mesh information is tabulated in Table 1.

During the processing step, the FLUENT code of CFD is used. This code is used for fluid flow, heat transfer, mass transfer, chemical reactions and such other processes. The concerned governing equations used in this study are given in Table 2 (ANSYS, 2011). The equations were solved iteratively and a converged solution was achieved.

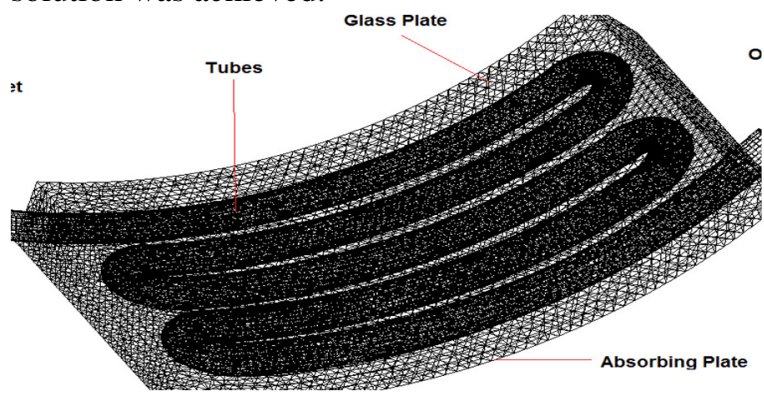

(a) Curved Plate Collector

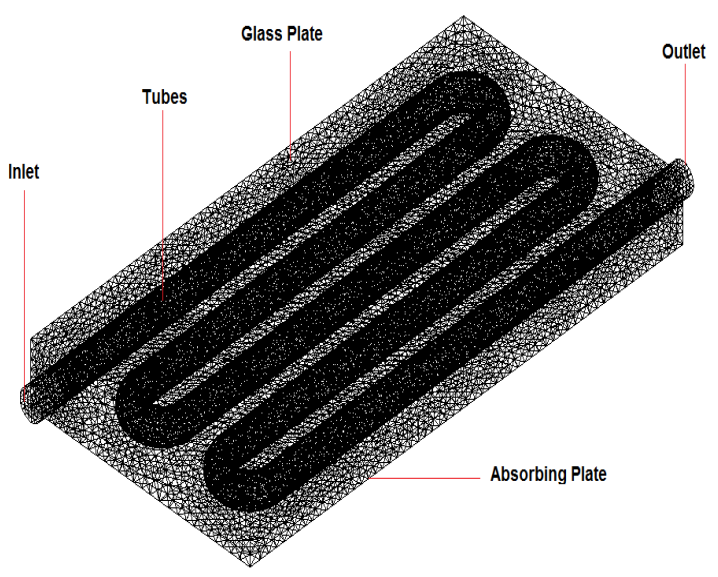

(b) Flat Plate Collector

Fig. 1: Computational Domains of Solar Collectors

The Computational fluid dynamics numerical methods are applied to solve a variety of composite problems with the help of USA company ANSYS, including the software FLUENT. These CFD techniques are based on FLUENT applications. They utilize algorithmic methodology with the assistance of computationally oriented mathematical determination. This work efficiently calculates the effects of solar hot light radiation done by poly to measure sunlight tracings. The irradiation model is applied to compute radiation results and overall effects are found.

Table 1: Overall dimensions of geometries and mesh information

\begin{tabular}{|c|c|c|}
\hline Parameter & Flat Plate & Curve Plate \\
\hline Length $\times$ Width & $\begin{array}{c}100 \mathrm{~cm} \times \\
50 \mathrm{~cm}\end{array}$ & $\begin{array}{c}100 \mathrm{~cm} \times 50 \\
\mathrm{~cm}\end{array}$ \\
\hline Thickness of Plate & $10 \mathrm{~cm}$ & $10 \mathrm{~cm}$ \\
\hline Diameter of tube & $5 \mathrm{~cm}$ & $5 \mathrm{~cm}$ \\
\hline $\begin{array}{c}\text { The material of the } \\
\text { upper plate } \\
\text { (Transparent) }\end{array}$ & Glass & Glass \\
\hline Material of Tube & Copper & Copper \\
\hline $\begin{array}{c}\text { The material of } \\
\text { absorbing plate }\end{array}$ & Graphite & Graphite \\
\hline Mesh Size & 323424 & 654324 \\
\hline $\begin{array}{c}\text { Type of Mesh } \\
\text { Tetrahedro } \\
\mathrm{n} \text { Cells }\end{array}$ & $\begin{array}{c}\text { Tetrahedro } \\
\mathrm{n} \text { Cells }\end{array}$ \\
\hline $\begin{array}{c}\text { Orthogonal quality } \\
\text { of mesh }\end{array}$ & 0.564 & 0.483 \\
\hline
\end{tabular}


Table 2: Few pre-selected governing equations for the CFD analysis

\begin{tabular}{|c|c|c|}
\hline $\begin{array}{l}\text { Type of } \\
\text { Equation }\end{array}$ & Mathematical Expression & $\begin{array}{l}\text { Eq. } \\
\text { No. }\end{array}$ \\
\hline Mass & $\nabla \cdot(\rho \vec{v})=S_{m}$ & (1) \\
\hline Momentum & $\nabla \cdot(\rho \overrightarrow{v v})=-\nabla p+\nabla \cdot(\hat{t})+\rho+\vec{F}$ & (2) \\
\hline Energy & $\begin{array}{l}\nabla \cdot(\vec{v}(\rho E+p)) \\
=\nabla \cdot\left(\lambda_{e f f} \nabla-\sum_{j} h_{j} \vec{J}_{j}\right. \\
\left.+\left(\overline{\bar{\tau}}_{\text {eff }} \cdot \vec{v}\right)+S_{h}\right)\end{array}$ & (3) \\
\hline $\begin{array}{l}\text { Standard } k-\varepsilon \\
\text { Turbulence } \\
\text { Mode }\end{array}$ & $\begin{aligned}-\rho \overline{\mathrm{u}_{\mathrm{i}}^{\prime} \mathrm{u}_{\mathrm{j}}^{\prime}}=\mathrm{u}_{\mathrm{t}}\left(\frac{\partial \mathrm{u}_{\mathrm{i}}}{\partial \mathrm{x}_{\mathrm{j}}}\right. & \left.+\frac{\partial \mathrm{u}_{\mathrm{j}}}{\partial \mathrm{x}_{\mathrm{i}}}\right) \\
& -\frac{2}{3} \rho \mathrm{k} \delta\end{aligned}$ & (4) \\
\hline $\begin{array}{l}\text { Radiation } \\
\text { Model }\left(\mathrm{P}_{1}\right)\end{array}$ & $-\nabla q_{r}=a G-4 a G \sigma a^{4}$ & (5) \\
\hline
\end{tabular}

In this work, the sun light tracing mode is found very significant and important because it calculates sun power loads for heat as medium and standard level power source average. Additionally, it solves energy equations. As a result, the Solar load is accessible in the farm of three-dimensional solver which is viable to employ on the model of the both flows steady and unsteady. On the grounds of time and date, the sunlight as solar rays is calculated with the help of the sun load model. Here radiation tracing phenomena are traceable by location of the sun in the atmosphere by applying algorithm techniques, which can calculate the sun position in a specific arrangement way. The ups and downs in the sun locations and position can also be calculated by the solar model vector, illumination modes. This position of sun gauging is revolved around whole wall boundary regions. This heat flux phenomenon, which is mathematically based can be numerically computed by using the ANSYS FLUENT Software. Here, one can observe very efficiently the directions of irradiation with the help of date, time, and zones by observing horizontal and vertical lines of latitude and longitude locations. The latitude concerned with far north or south is directly relative to the equator location. The Longitude angles up to 180 degrees indicate the position and exact locations in an east-west route, concerned with Greenwich Time of the whole Universe. Among global countries, this study focuses on one country China where eight prominent cities are chosen from their above-said latitude plus longitude lines. This comprehensive research was carried-out for each city at fixed days and time. Here in this work, time flow methods further subdivided the mesh, which helped to render computer simulations and provided the base for geometry surface calculations of the CFD. This phenomenon of numerical calculations was adopted for northeast directions. The mesh techniques are used for rendering to a computer physical simulation-based on geometry surface for crucial vector CFD. Here irradiation method was applied by managing north, east directions. The linear reduction factor was also part of this design, which was applied to sunrise and its other possibilities factor-like cloud. The fixed conditions for all simulations $\mathrm{A}$ to $\mathrm{Z}$ are tabulated in Table 3 .

\subsection{Assumptions and Convergence Criteria}

The main assumptions regarding this work include the following. High-temperature losses are ignored, and working liquid in the heat absorption process is considered as incompressible fluid in boundary conditions. The criteria of steady flows have been adopted. Simple mathematical methods have been used for generating the sun rays, management of energy and its utilization. Computational expedient basis the process of fluid flow areas as an axis tube where the fluid tendency and its overworking phenomenon are calculated. Moreover, the density, temperature thermal conductivity, and non-slip mode applications are calculated. Almost all wall surfaces, heat conduction oriented tube, and absorber shell conduction were calculated. Here in this study, plain algorithm applications and tools were applied in order to gauge the velocity and pressure of the fluid flow. All these process results were attained with the help of momentum residual turbulent, the kinetic energy and by mass converge.

\section{RESULTS AND DISCUSSION}

The computer-oriented CFD simulation on solar collectors as a mode of solar plates and curved plates modeling was done productively. The latitude and longitude information of eight cities of China was part of the work to investigate the solar radiation effects 
Table 3: Input conditions for various simulated cases

\begin{tabular}{|c|c|c|c|c|c|c|c|c|}
\hline Sr. No. & City & Latitude & Longitude & Date/Time & Feed Temp. & \multicolumn{2}{|c|}{$\begin{array}{c}\text { The mass flow rate of } \\
\text { working fluid (Kg/sec) }\end{array}$} \\
\hline 1 & Beijing (B) & 39.9042 & 116.4074 & 16-Jun/ 01:00 PM & $27^{\circ} \mathrm{C}$ & 0.005 & 0.01 & 0.015 \\
\hline 2 & $\begin{array}{c}\text { Changzhou } \\
\text { (CZ) }\end{array}$ & 31.8112 & 119.9741 & $25-\mathrm{Jul} / 01: 00 \mathrm{PM}$ & $27^{\circ} \mathrm{C}$ & 0.005 & 0.01 & 0.015 \\
\hline 3 & $\begin{array}{c}\text { Chongqing } \\
(\mathrm{CQ})\end{array}$ & 29.4316 & 106.9123 & $21-\mathrm{Jul} / 01: 00 \mathrm{PM}$ & $27^{\circ} \mathrm{C}$ & 0.005 & 0.01 & 0.015 \\
\hline 4 & Nanjing (N) & 32.0603 & 118.7969 & $25-\mathrm{Jul} / 01: 00 \mathrm{PM}$ & $27^{\circ} \mathrm{C}$ & 0.005 & 0.01 & 0.015 \\
\hline 5 & Shanghai (S) & 31.2304 & 121.4737 & 26-Jun/ 01:00 PM & $27^{\circ} \mathrm{C}$ & 0.005 & 0.01 & 0.015 \\
\hline 6 & Turfan (T) & 42.9513 & 89.1898 & 23-Jul/ 01:00 PM & $27^{\circ} \mathrm{C}$ & 0.005 & 0.01 & 0.015 \\
\hline 7 & Wuhan (W) & 30.5928 & 114.3055 & 27-Jul/ 01:00 PM & $27^{\circ} \mathrm{C}$ & 0.005 & 0.01 & 0.015 \\
\hline 8 & Xian (X) & 34.3416 & 108.9398 & 19-Jul/ 01:00 PM & $27^{\circ} \mathrm{C}$ & 0.005 & 0.01 & 0.015 \\
\hline
\end{tabular}

on working capacity of solar collector plates. The outlet temperatures of liquid flowing from flat and curved plate collectors at different cities with different flow-rates are shown in Fig. 2 and Fig. 3 respectively. No significant difference in the fluid's exit temperatures was observed with the change of the city. The probable reason for this is that the simulations were performed at the respective highest temperature levels as per meteorological information available. However, a significant difference in exit temperatures was noticed with the change in flow-rate and geometry of the collector. The highest temperature with a flat plate collector was observed up to $70^{\circ} \mathrm{C}$, with the lowest fluid flowrate of $0.005 \mathrm{Kg} / \mathrm{sec}$. The exit temperature dropped up to $46^{\circ} \mathrm{C}$, with an increase in the flow rate of $0.01 \mathrm{Kg} / \mathrm{sec}$. The exit temperature further decreased and reached about $38^{\circ} \mathrm{C}$, with a further increase in flowrate of $0.015 \mathrm{Kg} / \mathrm{sec}$. The apparent reason for this trend is the decreasing residence time due to increasing flow-rate and hence decrease in time for getting maximum heat transfer.

A similar trend has been observed in curved plate collectors, but exit temperatures showed little higher temperature levels with these flow-rates. The maximum exit temperature with curved plate geometry was achieved about $86^{\circ} \mathrm{C}$ at a low flow-rate of $0.005 \mathrm{Kg} / \mathrm{sec}$. The exit temperatures were observed about $57^{\circ} \mathrm{C}$ and $46^{\circ} \mathrm{C}$, at medium flowrate $(0.01$ $\mathrm{Kg} / \mathrm{sec})$ and fast flow-rate $(0.015 \mathrm{Kg} / \mathrm{sec})$, respectively. Hence it is concluded that curved plate collectors are performing well as compared to flat plate collectors with selected cities of China.

The temperature contours of flat and curved plate collectors at different cities with different flow-rates are shown in Fig.4 to 7. These contours help to understand the heat transfer behavior with different flow- rates and with different geometries placed in selected locations. It can be visualized that due to the curved surface, the SCPC shows better heat transfer.

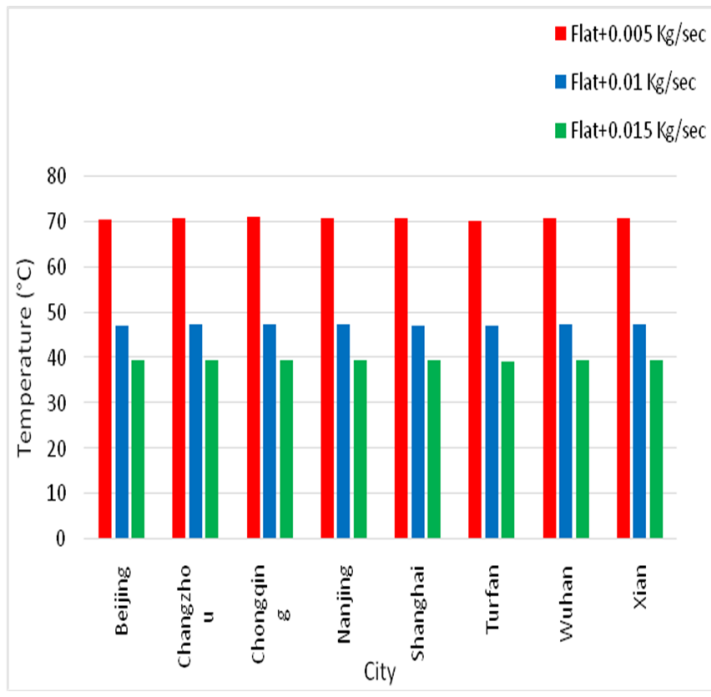

Fig. 2: Temperatures of operational fluid used for SFPC with eight china cities and varying flow-rates Mehran University Research Journal of Engineering and Technology, Vol. 40, No. 1, January 2021 [p-ISSN: 0254-7821, e-ISSN: 2413-7219] 


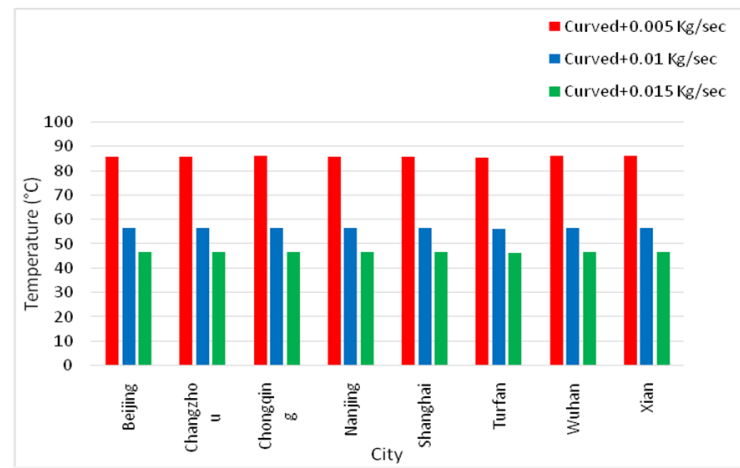

Fig. 3: Depart temperatures of functioning fluid regarding SCPC with eight unlike cities of China and varying flow-rates

\section{CONCLUSION}

The solar flat plate and curved plate collectors (SFPC and SCPC) were numerically simulated in this research study. The solar beams tracing model equations were solved along with general flow and continuity equations. Eight cities of China were selected to investigate the performance of SFPC and SCPC. The analysis was conducted with 3 different flow-rates 0.005 kilogram /second, 0.010 Kilogram/second and 0.015 kilogram/second. Water was used as a fluid for investigating the performance. It was concluded that different cities have no major impact on the overall performance of SFPC or SCPC. However, curved plate geometry is shown better results over flat plate geometry. Curved plate increased $22 \%$ more temperatures of outgoing water as compared with flat plate collectors. Moreover, the great influence of fluid's flow-rate has been observed on the overall performance of collectors with either geometry. An increase in flow-rate decreases the performance in terms of dropping the exit temperature. The work could be extended by conducting transient simulations, and even different times would also be incorporated in future simulations.

\section{REFERENCES}

[1] Al-Hamadanim, S., "Solar energy as a potential contributor to help bridge the gap between electricity supply and growing demand in Iraq: A review", International Journal of Advances in Applied Sciences, Vol. 9, No. 4, , pp. 302 312, 2020.
Huang Z., Mendis T., Xu S., "Urban (2019) solar utilization potential mapping via deep learning technology: A case study of Wuhan, China", Applied Energy, Vol. 250, No. 15, pp. 283-291, 2019.

[3] Tagliafico L.A., Scarpa F., De Rosa M., "Dynamic thermal models and CFD analysis for flat-plate thermal solar collectors - A review", Renewable and Sustainable Energy Reviews, Vol. 30, pp. 526-537, 2015.

[4] Dong J., Xue G., Dong M., Xu X., 2015), "Saving power generation dispatching in China: regulations, pilot projects and policy recommendations-a Review", Renewable and Sustainable Energy Review, Vol. 43, pp. 1285-1300, 2015.

[5] Wood N., Roelich K., "Tensions, capabilities, and justice in climate change mitigation of fossil fuels", Energy Research and Social Science, Vol. 52, pp. 114-122, 2019.

[6] Aleixandre-Tudó J.L., Lourdes CastellóCogollos, Aleixandre R., "Renewable energies: Worldwide trends in research, funding, and an international collaboration" Renewable Energy, Vol. 139, pp 268-278, 2019.

[7] Jassim N.A., Shbailt S.J., "Threedimensional, CFD Analysis for Simulating Dual Channel Solar Collector with Different Absorbing Media", Renewal and Sustainable Energy Reviews, Vol. 43, pp. 1285-1300, 2015.

[8] Hassan J.M., Qussai J., Ghafour A., Mohammed M.F., CFD, "Simulation of Enhancement Techniques in Flat Plate Solar Water Collectors", AL-Nahrain Journal for Engineering Sciences, Vol. 20, No.3, pp 751-761, 2017.

[9] Qin X., Shen Y., Shao S., "The Application Study in Solar Energy Technology for Highway Service Area: A Case Study of West Lushan Highway Low-Carbon Service Area in China", International Journal of Photoenergy, Vol. 201, 2015.

[10] Jichai Z.W., Hohgwei, "Integrated Evaluation of Coupling Coordination for Land Use Change and Ecological Security: A Case Study in Wuhan City of Hubei Province of China”, International Journal of 
Environmental Research and Public Health, Vol. 14, No. 11, 2017.

[11] Unar I.N., Maitlo G., Ahmed S., Ali S.S., Memon A.Q., Kandhro G.A., Jatoi A.S., "Performance evaluation of solar flat plate collector using, different working fluids fluid through computational fluid dynamics, $S N$ Applied Sciences, Vol. 2, No. 2, p.209, 2020.

[12] Huang J., Tian Z., Fan J., "A comprehensive analysis on development and transition of the solar thermal market in with more than $70 \%$ market share worldwide", Energy, Vol. 174, No. 1, pp. 611-624, 2019.

[13] Piyus K., Pathak. P., Chandra, Gaurv R., "Experimental and CFD analyses of corrugated -plate solar collector by force convection", Energy Sources, Part A: Recovery, Utilization and Environment Effects, Vol. 42, 2020.

[14] Tagliafico L.A., Scarpa F., De Rosa M., Dynamic thermal models and CFD analysis for flat-plate thermal solar collectors - A review, Renewable and Sustainable Energy Reviews, Vol. 30, pp. 526-537, 2014.

[15] Baig M.M., Khan M.A.,Mohi Uddin M.K., Calculation and Fabrication of a Solar Flat Plate Collector efficiency using Mild Steel as absorber Plate, International Journal of Science Technology and Engineering, Vol. 3, No. 08, 2017.
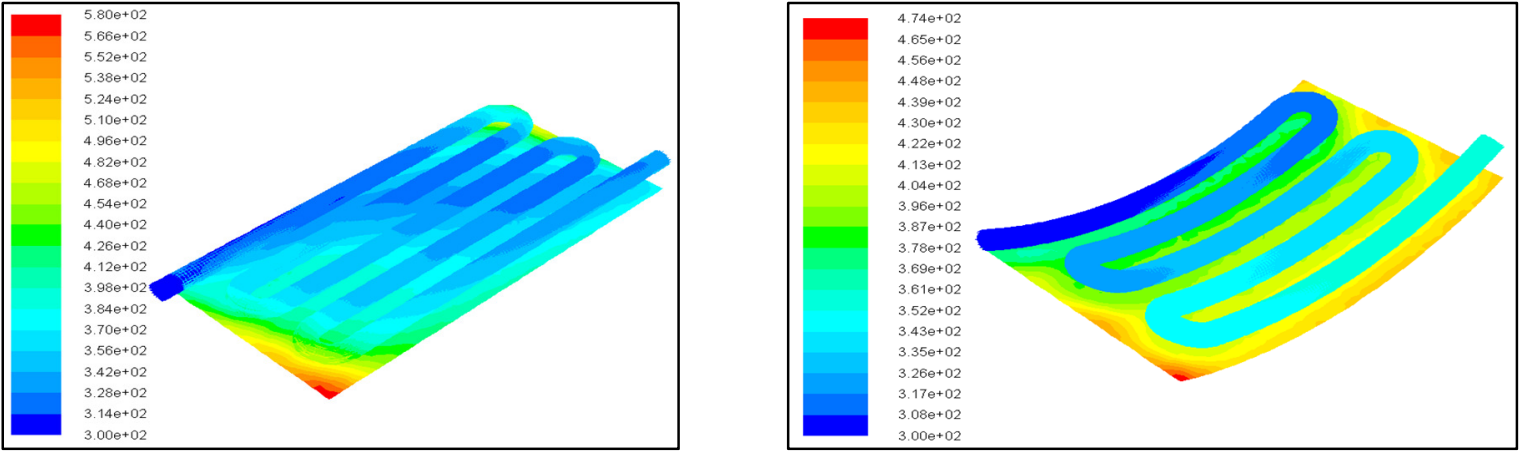

(a) $0.005 \mathrm{kilo}-\mathrm{gram} / \mathrm{second}$ fluid flow-rate
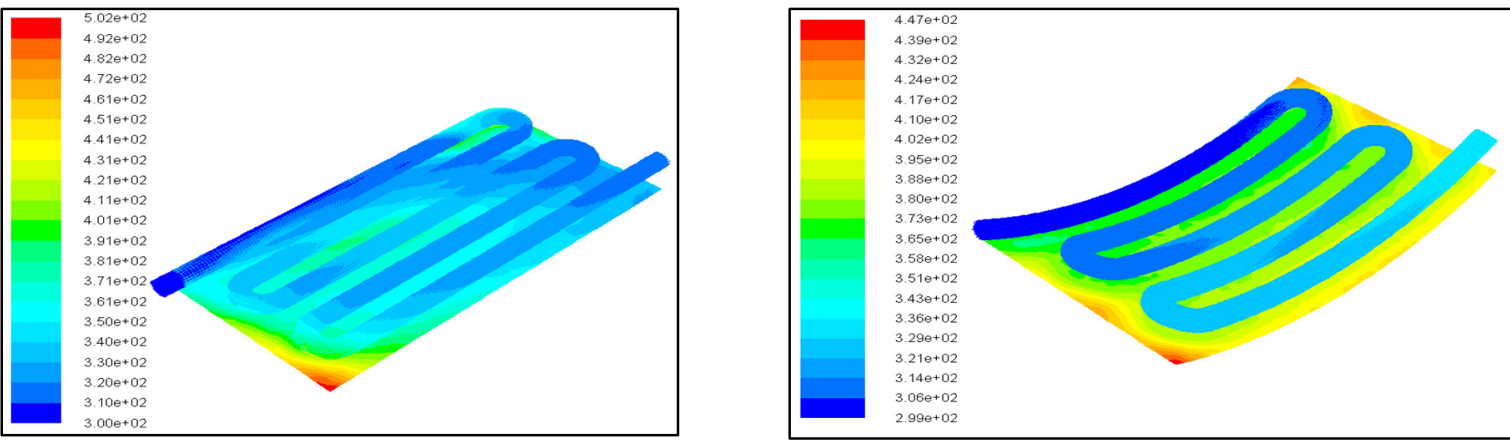

(b) 0.01 kilo-gram/second fluid flow-rate
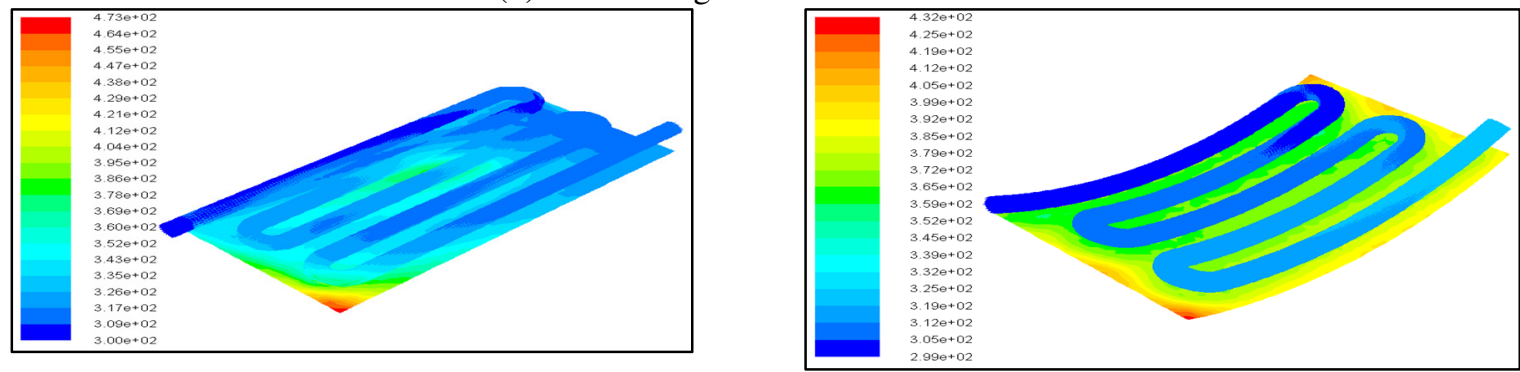

(c) 0.015 kilo-gram/second fluid flow-rate

Fig. 4: Temperature Contours of SFPC and SCPC for Beijing City 

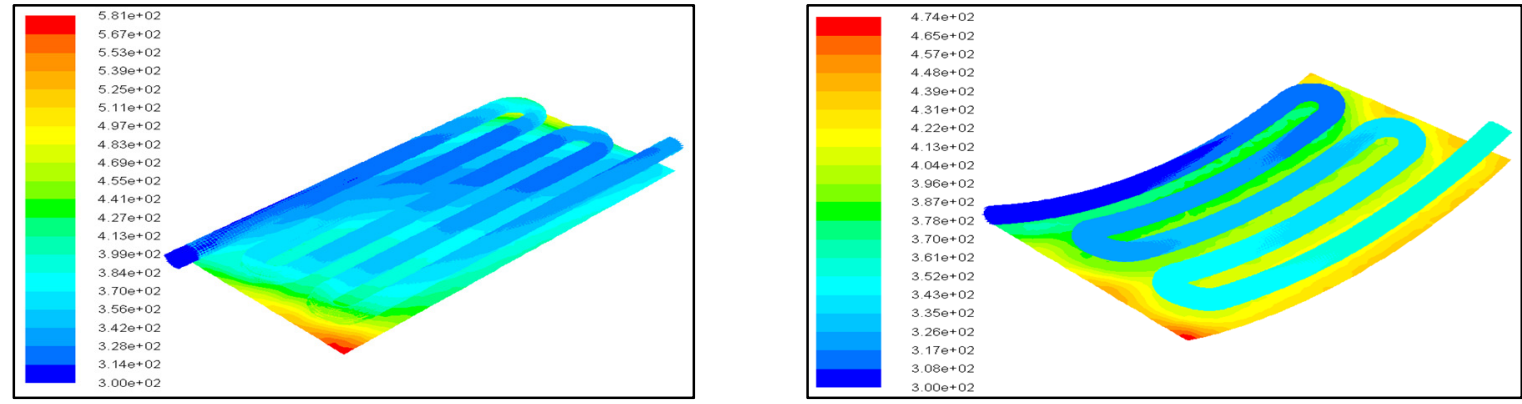

(a) $0.005 \mathrm{kilo}-\mathrm{gram} / \mathrm{second}$ fluid flow-rate
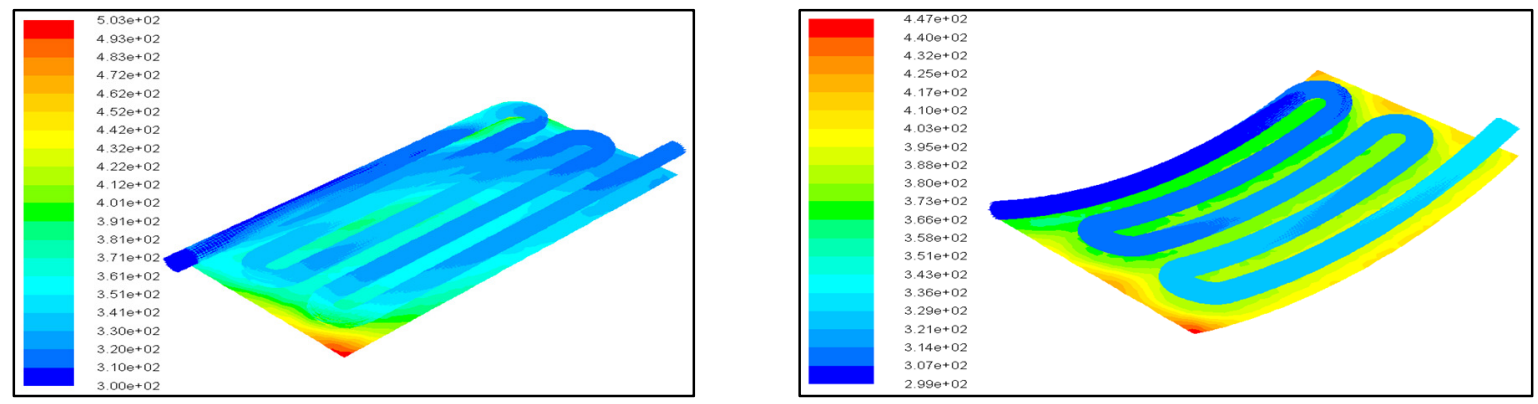

(b) 0.01 kilo-gram/second fluid flow-rate
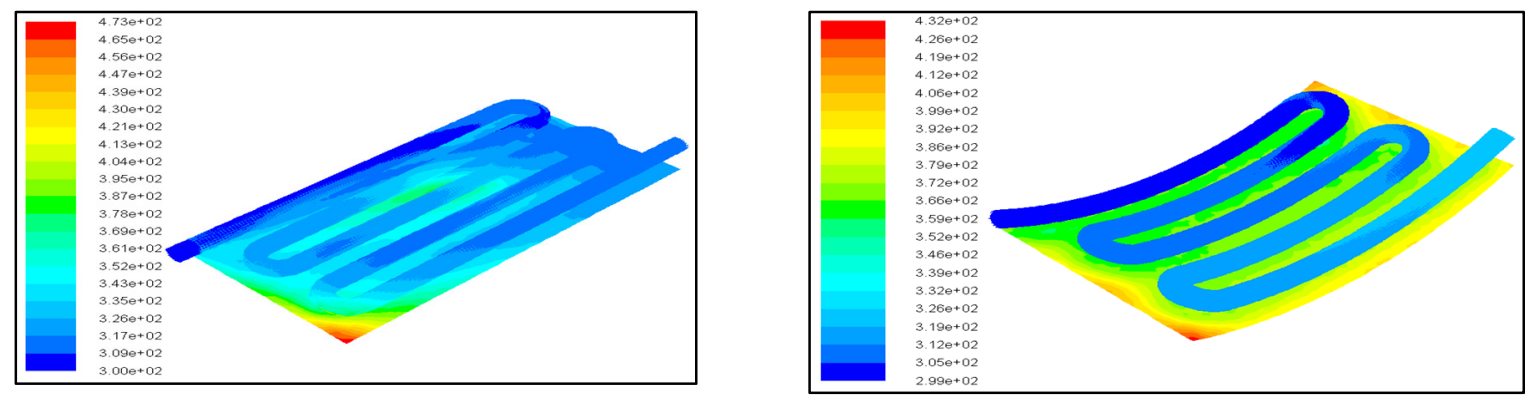

(c) 0.015 kilo-gram $/ \mathrm{sec}$ fluid flow-rate

Fig. 5: Temperature Contours of SFPC and SCPC for Changzhou City
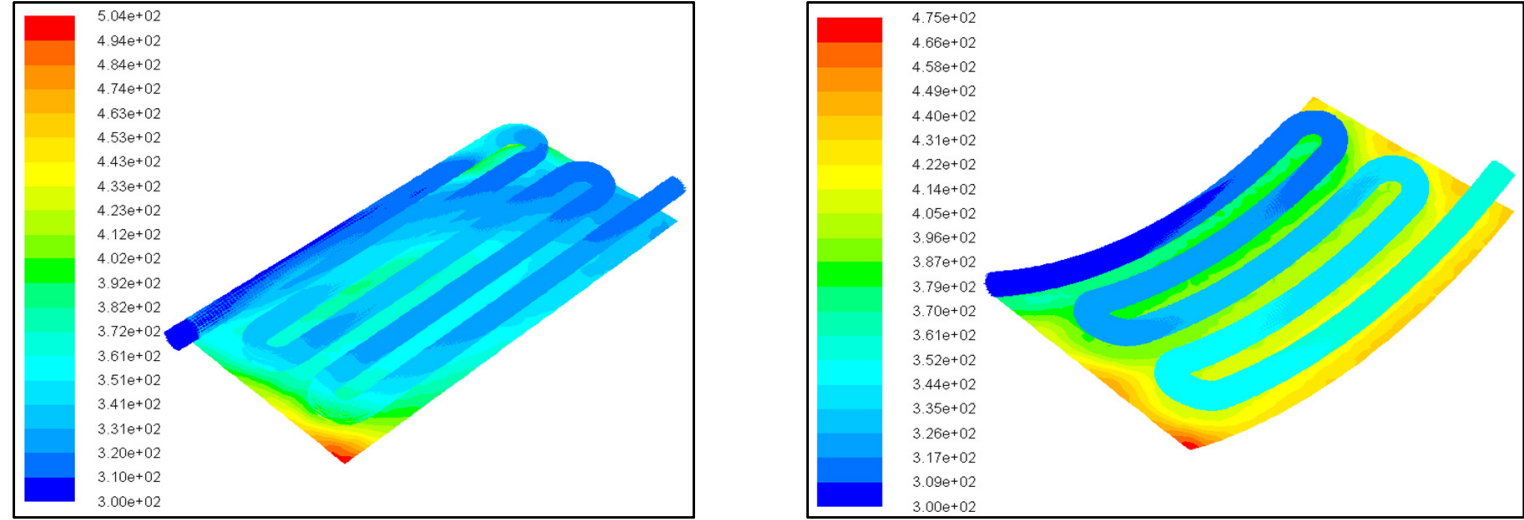

(a) 0.005 kilo-gram/second fluid flow-rate 

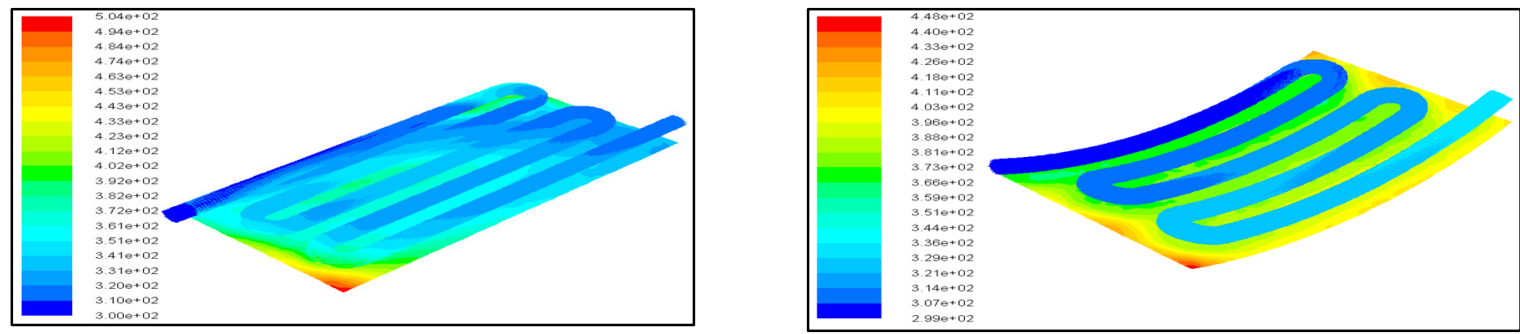

(b) 0.01 kilo-gram /second fluid flow-rate
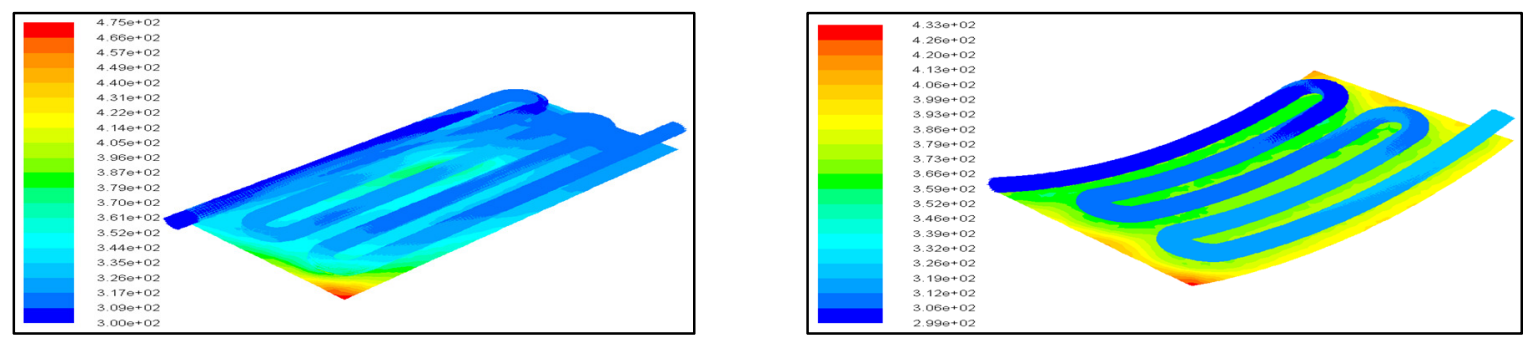

(c) 0.015 kilo-gram/second fluid flow-rate

Fig. 6: Temperature Contours of SFPC and SCPC for Chongqing City
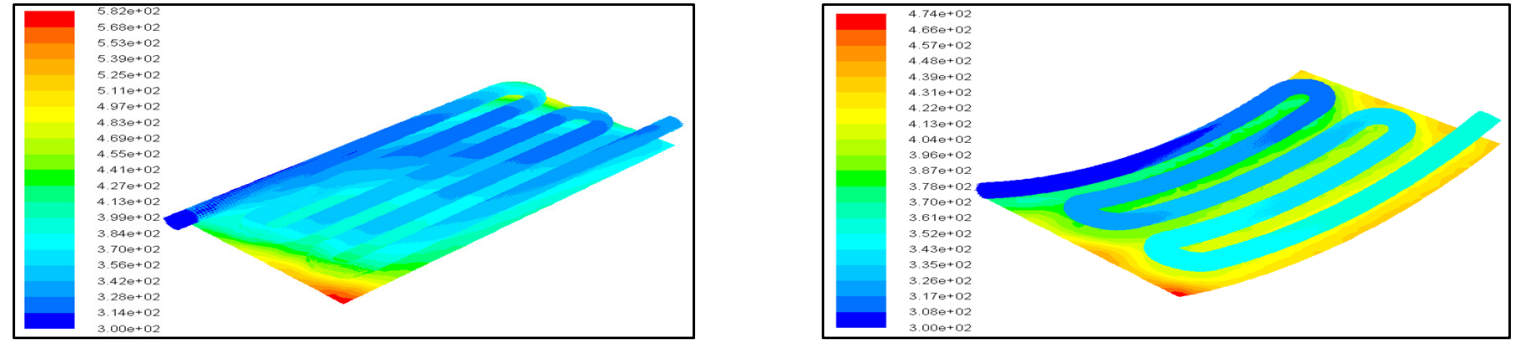

(a) $0.005 \mathrm{kilo-gram} / \mathrm{sec}$ fluid flow-rate
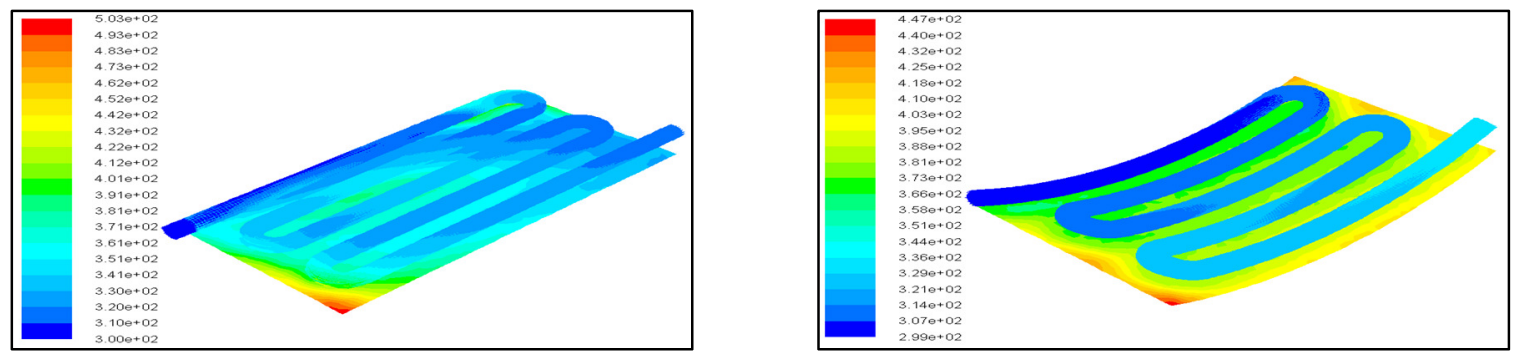

(b) 0.01 kilo-gram /second fluid flow-rate
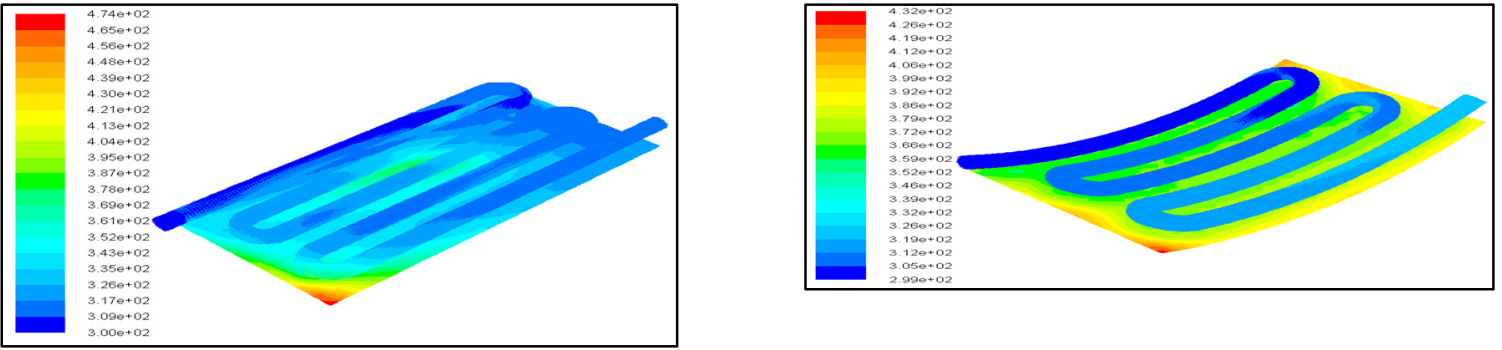

(c) 0.015 kilo-gram/second fluid flow-rate

Fig. 7: Temperature Contours of SFPC and SCPC for Nanjing City 